\title{
Motivations for responses to ostracism
}

\author{
Eric D. Wesselmann ${ }^{1}$, Dongning Ren ${ }^{2}$ and Kipling D. Williams ${ }^{2}$ \\ 1 Department of Psychology, Illinois State University, Normal, IL, USA \\ ${ }^{2}$ Department of Psychological Sciences, Purdue University, West Lafayette, IN, USA \\ *Correspondence: edwesse@ilstu.edu \\ Edited by: \\ Christina Steindl, University of Salzburg, Austria \\ Reviewed by: \\ Nilüfer Aydin, Alpen-Adria University, Germany \\ Michaela Pfundmair, Ludwig-Maximilians University of Munich, Germany
}

Keywords: ostracism, social exclusion, rejection, pro-social behavior, anti-social behavior

Ostracism (being ignored and excluded) and other forms of interpersonal rejection threaten individuals physical and psychological well-being (Williams and Nida, 2011). Researchers often use the terms ostracism, social exclusion, and rejection interchangeably, but there are theoretical and empirical debates about the differential effects of these phenomena (Smart Richman and Leary, 2009; Williams, 2009; Bernstein and Claypool, 2012). We acknowledge these debates but choose to use the term ostracism ubiquitously for simplicity because most of the outcomes we discuss are similar across the phenomena. Most individuals experience these threats at least once during their lives, and some individuals experience them daily (Williams, 2009).

Regardless of the mode or source by which the event occurs, ostracism threatens basic psychological needs (belonging, control, meaningful existence, and selfesteem; Nezlek et al., 2012; Wesselmann et al., in press). Williams (2009) posits a temporal structure to ostracism's effects. In Stage 1, ostracism's basic need threat is ubiquitous with few situational or dispositional moderators (Wesselmann et al., in press). Williams's model is motivationfocused; after the initial threat occurs, individuals should be motivated to recover by fortifying their threatened needs. Stage 2 focuses on cognitive and behavioral processes ostracized individuals use to recover. Stage 3 argues that chronically ostracized individuals withdraw socially and experience extreme psychological and physical damage. We will now focus on relevant Stage 2 research and then discuss suggestions for future research on Stages 2 and 3.

\section{STAGE 2: REFLECTION AND RECOVERY}

Experimental data suggest that recovery can begin within minutes after ostracism occurs and participants use multiple cognitive and behavioral strategies to recover their thwarted basic needs. Individuals' cognitive strategies often focus on attributions for why ostracism occurred and ways to remedy the situation (Williams, 2009). Wirth and Williams (2009) found that attributions influence recovery speed: Individuals attributing ostracism to an experimentally contrived group membership recovered from ostracism quicker than individuals who attributed ostracism to a permanent group membership (i.e., gender; also race in Goodwin et al., 2010; c.f., Masten et al., 2011). Another effective strategy involves encouraging participants to recall ostracism from an outsider's (compared to first-person) perspective (Lau et al., 2009). Also, research demonstrates that priming feelings of physical invulnerability reduces the need for ostracized participants to seek various cognitive and interpersonal recovery options (Huang et al., 2013). Self-construal also facilitates recovery from ostracism: Individuals who have higher interdependent/collectivistic selfconstruals (i.e., define themselves in terms of social relationships) can recover quicker from ostracism compared to individuals who are lower in these construals (Ren et al., 2013; Pfundmair et al., 2015). Finally, reminding someone of positive social relationships, symbolic/parasocial relationships, or religious/spiritual affiliations facilitates recovery from ostracism (Gardner et al., 2005; Twenge et al., 2007; Epley et al., 2008; Derrick et al., 2009; Aydin et al.,
2010, 2012; McConnell et al., 2011; Laurin et al., 2014).

Research on behavioral strategies focus mostly on pro- or anti-social behaviors and how they facilitate basic need recovery (Williams, 2009). Experimental research demonstrates that ostracized individuals respond more pro-socially than included individuals; they attend more to social information relevant to inclusion (Pickett et al., 2004; Bernstein et al., 2008; Böckler et al., 2014), work harder on group tasks (at least among women participants; Williams and Sommer, 1997), focus more on re-inclusion (Maner et al., 2007; Molden et al., 2009), and show increased sensitivity to social influence (Williams et al., 2000; Carter-Sowell et al., 2008; Riva et al., 2014b). Ostracized individuals also respond more anti-socially than included individuals. Ostracized individuals respond aggressively toward another person regardless of whether this person ostracized them. Researchers have measured aggression using diverse methods, such as temptations for physical and social aggression, negative evaluations, unpleasant noise, and ostensibly forcing someone to eat hot sauce (Twenge et al., 2001; Buckley et al., 2004; Warburton et al., 2006).

These two behavioral patterns seem contradictory, but Williams (2009) theorizes that each type of behavior should be linked to the specific psychological needs threatened by ostracism. Pro-social behaviors should be more likely to fortify inclusionary needs (belonging and self-esteem) because these behaviors are more likely to achieve re-inclusion; antisocial behaviors should be more likely to fortify power/provocation needs (control 
and meaningful existence) because these behaviors will likely provoke acknowledgement from the ostracizers (see also Gerber and Wheeler, 2009). Ostracized individuals should focus on fortifying whichever need group is most salient to them; ostracized individuals who are unlikely (or unable) to be re-included into a group should focus more on fortifying power/provocation needs (via anti-social behavior) because these needs would be easier to fortify than inclusionary needs (Williams and Wesselmann, 2011).

Experimental research supports Williams's need fortification argument, specifically for control and aggression. Warburton et al. (2006) demonstrated that fortifying ostracized participants' control need immediately after ostracism reduced their aggressive responses to the same level as included participants, whereas unfortified ostracized participants continued to aggress. Schoel et al. (2014) found that ostracized individuals' threatened control (but not the other needs) mediated the ostracism $\rightarrow$ aggression effect. Other research investigates inclusionary needs and pro-social behavior. Ostracized participants afforded re-connection opportunities behaved less aggressively than ostracized participants not afforded this option (Twenge et al., 2007; DeWall et al., 2010). Pfundmair et al. (2014) investigated the interaction between self-construal and oxytocin (a hormone typically linked to pro-social behavior) on ostracized individuals' reactions (specifically, belonging and self-esteem threat). They found that collectivistic-oriented individuals exposed to oxytocin showed reduced need threat compared to individuals exposed to the placebo, suggesting that simple hormonal cues of affiliation can provide temporary relief from ostracism (at least for individuals who emphasize social relationships in their self-concept). Finally, Bernstein et al. (2010) demonstrated that ostracized participants showed more desire to interact with new sources of affiliation than included participants; this pro-social orientation was mediated by ostracized participants' threatened inclusionary needs. Interestingly, they tested both self-esteem and belonging against each other in a multiple-mediation model and found that self-esteem was a stronger mediator than belonging, suggesting potential nuances within each need cluster that future research should investigate.

\section{FUTURE RESEARCH QUESTIONS \\ Paradoxical Responses?}

Future research needs to address directly these two conflicting behavioral responses. Often, researchers only give participants one behavioral option. Because of this, it is hard to rule out the possibility that ostracized participants are simply responding more extremely than included participants using whatever option they are given because it is the only option they have to fortify some of their basic needs. Some behavioral measures can be interpreted as pro- or anti-social depending on how participants respond (Gerber and Wheeler, 2009). For example, allocating high amounts of hot sauce to someone who hates spicy food fits the conceptual definition of aggression, but the experimenter instructs participants that they have to allocate some amount (whether they choose a small or large amount). Thus, participants who give a small amount could be interpreted as either being less aggressive or potentially more pro-social because they are obeying the experimenter nominally but also not subjecting the target to unnecessary discomfort. Further, how do researchers categorize participants who actively choose not to allocate any hot sauce at all? Is this simply lack of aggression or also an independent pro-social behavior toward the target?

Recent evidence suggests these two responses might coexist: ostracized individuals seek social connections to an interacting partner (pro-social) and devaluate the same target (anti-social) simultaneously (Sommer and Bernieri, 2014). Gerber and Wheeler (2009)'s meta-analysis found that when forced to choose, participants usually favored anti-social (i.e., control-focused) options. Domachowska et al. (2014) found that ostracized participants preferred higher impact responses (either pro- or antisocial), toward new individuals. They only preferred anti-social responses toward the ostracizers. These findings suggest a complex relationship between behaviors, need satisfaction, and contextual factors. Future research should consider merging these findings with other theoretical models. For example, the Meaning Maintenance Model (Heine et al., 2006) argues that when individuals experience threats to their sense of meaning, they seek recovery either through re-affirming meaning in the threatened domain or indirectly by affirming a symbolically-related domain. Ostracism research typically focuses on threats to four basic needs that are conceptually distinct but inter-correlated (Williams, 2009). It is possible that ostracized individuals can focus on fortifying one specific need (or cluster) and indirectly fortify the others by proxy. Thus, anti-social behaviors may fortify control the most but also may fortify the other three needs in smaller degrees.

Other threat-focused models [e.g., rejection-based threats, Smart Richman and Leary (2009), or threats more broadly, Jonas et al. (2014)] may also offer interesting ways of understanding when and why individuals respond pro- or anti-socially. Jonas et al. (2014) argue that there is a temporal structure to psychological reactions to threat, beginning with anxiety and inhibition or avoidance-based behaviors. Their theorized immediate effects converge with Williams's (2009) argument for Stage 1 reactions to ostracism. Jonas et al. (2014) argues that certain reactions move beyond immediate inhibition-based responses and facilitate approach-oriented behaviors; these behaviors can either address the threat directly or symbolically. The research focused on Williams's (2009) Stage 2 can be re-framed within this theoretical context. Both pro-social and anti-social behaviors could be considered approach-oriented; although pro-social behaviors are the most likely to achieve re-inclusion and primarily fortify the inclusionary needs, anti-social behaviors can also facilitate recovery via the power/provocation needs. The research on cognitive strategies can also be considered approach-oriented in that they either actively help individuals recover need satisfaction through attributional reframing or address the threat symbolically via affirming one's other interpersonal or parasocial relationships.

Researchers could also measure theoretically meaningful individual difference variables to test potential moderation of the anti-social/pro-social paradox. For 
example, ostracized participants who have a higher dispositional need to belong (Leary et al., 2013) should be more likely to favor pro-social responses (linked to inclusionary needs) than anti-social responses (linked to power/provocation needs). Also, ostracized individuals who are oriented more toward long-term rather than shortterm future outcomes respond with higher pro-social behavior than those who favor short-term outcomes instead (Balliet and Ferris, 2013). It is possible that a long-term focus would allow ostracized individuals an edge in overcoming an initial impulse to respond with anger and aggression, thus making inclusionary needs the primary focus. Other research demonstrates that socially anxious individuals recover more slowly (Zadro et al., 2006) and respond less pro-socially when ostracized (Mallott et al., 2009). As social anxious individuals find any social interaction aversive, it is possible these individuals would be less likely to want re-inclusion after ostracism and thus inclusionary needs would be less salient to fortify.

Some individual differences should moderate anti-social responses. Individuals higher in rejection sensitivity (i.e., the tendency to expect and easily perceive rejection; Ayduk et al., 2008) or destiny beliefs (Chen et al., 2012) respond more aggressively than ostracized participants lower in these individual differences. Ostracized individuals high in these latter two variables likely assume that their treatment is consistent with how they will be treated in future interactions; thus the power/provocation need cluster should be most salient to them, facilitating anti-social over pro-social behaviors. Interestingly, ostracized individuals who are high in narcissism also respond more negatively to ostracism than other individuals (Twenge and Campbell, 2003). Narcissistic individuals should expect ubiquitous inclusion because of their inflated self-esteem and may assume the ostracism was anomalous. However, this attribution would not explain their increased aggression using our future expectations argument. Wesselmann et al. (2010) offer another possibility: Unexpected ostracism provokes more aggression than expected ostracism, likely because it suggests an inability to read social cues accurately which in turn suggests threats to future social inclusion. Narcissists typically prioritize being admired over being liked (Morf and Rhodewalt, 2001), but they would need to accurately read social cues regardless. Thus, unexpected ostracism would still be more threatening than expected ostracism.

\section{Chronic Ostracism}

Williams (2009) developed Stage 3 by synergizing qualitative interviews of chronically ostracized individuals with other related psychological topics. Chronically ostracized individuals who find their attempts at recovery (Stage 2) continually thwarted should become resigned to their fate and face extreme negative consequences (i.e., feelings of alienation, depression, helplessness, and meaninglessness). Further, chronically ostracized individuals may seek solitude or otherwise disengage from relationships to avoid future ostracism or other unpleasant social interactions (Leitner et al., 2014; Wesselmann et al., 2014). We consider this social withdrawal a flight response (compared with fight responses, i.e., proand anti-social behaviors; Williams, 2007; see also Smart Richman and Leary, 2009; Pfundmair et al., 2015). Additionally, a freeze response (Williams, 2007) may encapsulate the cognitive, physical, and affective numbness that sometimes characterizes chronic loneliness and extreme social pain manipulations (e.g., being told one will spend their entire lives alone; DeWall and Baumeister, 2006; Blackhart et al., 2009; Bernstein and Claypool, 2012; Riva et al., 2014a). Few studies have considered these latter two options regarding psychological need threat and recovery, especially within Williams's (2009) temporal model. This area begs for future research and should consider combining Williams's (2009) model with other threat-based models (e.g., Smart Richman and Leary, 2009; Jonas et al., 2014) to derive predictions regarding flight and freeze responses.

Chronically ostracized individuals may also be susceptible to recruitment by predatory/extreme groups because these groups may offer a last bastion of inclusion (Wesselmann and Williams, 2010; Williams and Wesselmann, 2011). Because ostracized individuals are susceptible to social influence involving mundane behaviors it may also occur for extreme behaviors. For example, Kruglanski et al. (2009; Kruglanski and Orehek, 2011) argue terrorists interpret their actions as a quest for meaning/significance (also Jonas et al., 2014). Individuals (or groups) who believe that they have been humiliated, marginalized, or ostracized by larger communities may be attracted to extremist groups endorsing terrorist actions to regain a sense of significance or control (Kruglanski, 2003). Other research examining mass violence in schools suggest that that actual or perceived ostracism was a primary motivator for perpetrators (Leary et al., 2003) so it is reasonable to extend this rationale to understanding violence perpetrated by groups of disaffected individuals such as terrorist organizations. These questions offer exciting research opportunities for understanding how ostracism's psychological threats can inspire the worst in individuals and how society can combat these effects.

\section{REFERENCES}

Aydin, N., Fischer, P., and Frey, D. (2010). Turing to god in the face of ostracism: effects of social exclusion on religiousness. Pers. Soc. Psychol. Bull. 36, 742-753. doi: 10.1177/01461672103 67491

Aydin, N., Krüger, J., Fischer, J., Han, D., Frey, D., Kastenmüller, A., et al. (2012). Man's best friend-how the presence of a dog decreases mental distress after social exclusion. J. Exp. Soc. Psychol. 48, 446-449. doi: 10.1016/j.jesp.2011.09.011

Ayduk, Ö., Gyurak, A., and Luerssen, A. (2008). Individual differences in the rejection-aggression link in the hot sauce paradigm: the case of rejection sensitivity. J. Exp. Soc. Psychol. 44, 775-782. doi: 10.1016/j.jesp.2007.07.004

Balliet, D., and Ferris, D. (2013). Ostracism and prosocial behavior: a social dilemma perspective. Organ. Behav. Hum. Decis. Process. 120, 298-308. doi: 10.1016/j.obhdp.2012.04.004

Bernstein, M. J., and Claypool, H. M. (2012). Not all social exclusions are created equal: emotional distress following social exclusion is moderated by exclusion paradigm. Soc. Influence 7, 113-130. doi: 10.1080/15534510.2012.664326

Bernstein, M. J., Sacco, D. F., Brown, C. M., Young S. G., and Claypool, H. M. (2010). A preference for genuine smiles following social exclusion. J. Exp. Soc. Psychol. 46, 196-199. doi: 10.1016/j.jesp.2009.08.010

Bernstein, M. J., Young, S. G., Brown, C. M., Sacco, D. F., and Claypool, H. (2008). Adaptive responses to social exclusion: social rejection improves detection of real and fake smiles. Psychol. Sci. 19 , 981-983. doi: 10.1111/j.1467-9280.2008.02187.x

Blackhart, G. C., Knowles, M. L., Nelson, B. C., and Baumeister, R. F. (2009). Rejection 
elicits emotional reactions but neither causes immediate distress nor lowers self-esteem: a metaanalytic review of 192 studies on social exclusion. Pers. Soc. Psychol. Rev. 13, 269-309. doi: 10.1177/1088868309346065

Böckler, A., Hömke, P., and Sebanz, N. (2014). Invisible man: exclusion from shared attention affects gaze behavior and self-reports. Soc. Psychol. Pers. Sci. 5, 140-148. doi: 10.1177/1948550613488951

Buckley, K. E., Winkel, R. E., and Leary, M. R. (2004). Reactions to acceptance and rejection: effects of level and sequence of relational evaluation. J. Exp. Soc. Psychol. 40, 14-28. doi: 10.1016/S00221031(03)00064-7

Carter-Sowell, A. R., Chen, Z., and Williams, K. D. (2008). Ostracism increases social susceptibility. Soc. Influence 3, 143-153. doi: 10.1080/15534510802204868

Chen, Z., DeWall, C. N., Poon, K., and Chen, E. (2012). When destiny hurts: implicit theories of relationships moderate aggressive responses to ostracism. J. Exp. Soc. Psychol. 48, 1029-1036. doi: 10.1016/j.jesp.2012.04.002

Derrick, J. L., Gabriel, S., and Hugenberg, K. (2009). Social surrogacy: how favored television programs provide the experience of belonging. J. Exp. Soc. Psychol. 45, 352-362. doi: 10.1016/j.jesp.2008.12.003

DeWall, C. N., and Baumeister, R. F. (2006). Alone but feeling no pain: effects of social exclusion on physical pain tolerance and pain threshold, affective forecasting, and interpersonal empathy. J. Pers. Soc. Psychol. 91, 1-15. doi: 10.1037/0022-3514. 91.1.1

DeWall, C. N., Twenge, J. M., Bushman, B., Im, C., and Williams, K. D. (2010). A little acceptance goes a long way: applying social impact theory to the rejection-aggression link. Soc. Psychol. Pers. Sci. 1, 168-174. doi: 10.1177/1948550610361387

Domachowska, I., Schade, H., Mitchell, A., and Williams, K. D. (2014). Hurt or Help, I Just Want to Matter: Reconciling Prosocial and Aggressive Responses to Ostracism. Amsterdam: European Association of Experimental Social Psychology.

Epley, N., Akalis, S., Waytz, A., and Cacioppo, J. T. (2008). Creating social connection through inferential reproduction: loneliness and perceived agency in gadgets, gods, and greyhounds. Psychol. Sci. 19, 114-120. doi: 10.1111/j.1467-9280.2008.02056.x

Gardner, W., Pickett, C. L., and Knowles, M. (2005). "Social snacking and shielding: using social symbols, selves, and surrogates in the service of belonging needs," in The Social Outcast: Ostracism, Social Exclusion, Rejection, and Bullying, eds K. D. Williams, J. P. Forgas, and W. Von Hippel (New York, NY: Psychology Press), 227-242.

Gerber, J., and Wheeler, L. (2009). On being rejected: a meta-analysis of experimental research on rejection. Perspect. Psychol. Sci. 4, 468-488. doi: 10.1111/j.1745-6924.2009.01158.x

Goodwin, S. A., Williams, K. D., and CarterSowell, A. R. (2010). The psychological sting of stigma: the costs of attributing ostracism to racism. J. Exp. Soc. Psychol. 46, 612-618. doi: 10.1016/j.jesp.2010.02.002

Heine, S. J., Proulx, T., and Vohs, K. D. (2006). The meaning maintenance model: on the coherence of social motivations. Pers. Soc. Psychol. Rev. 10, 88-110. doi: 10.1207/s15327957pspr1002_1

Huang, J. Y., Ackerman, J. M., and Bargh, J. A. (2013). Superman to the rescue: simulating physical invulnerability attenuates exclusion-related interpersonal biases. J. Exp. Soc. Psychol. 49, 349-354. doi: 10.1016/j.jesp.2012.12.007

Jonas, E., McGregor, I., Klackl, J., Agroskin, D., Fritsche, I., Holbrook, C., et al. (2014). "Threat and defense: from anxiety to approach," in Advances in Experimental Social Psychology, Vol. 49, eds J. M. Olson and M. P. Zanna (New York, NY: Academic), 219-286.

Kruglanski, A. W. (2003, April). Terrorism as a tactic of minority influence. Paper presented at F. Buttera and J. Levine (Chairs). Active Minorities: Hoping and Coping. Grenoble, France.

Kruglanski, A. W., Chen, X., Dechesne, M., Fishman, S., and Edward, O. (2009). Fully committed: suicide bombers' motivation and the quest for personal significance. Political Psychol. 30, 331-357. doi: 10.1111/j.1467-9221.2009.00698.x

Kruglanski, A. W., and Orehek, E. (2011). "The role of the quest for personal significance in motivating terrorism," in The Psychology of Social Conflict and Aggression, eds J. P. Forgas, A. W. Kruglanski, and K. D. Williams (New York, NY: Psychology Press), 153-164.

Lau, G., Moulds, M. L., and Richardson, R. (2009). Ostracism: how much it hurts depends on how you remember it. Emotion 9, 430-434. doi: 10.1037/a0015350

Laurin, K., Schumann, K., and Holmes, J. G. (2014). A relationship with God? Connecting with the divine to assuage fears of interpersonal rejection. Soc. Psychol. Pers. Sci. 5, 777-785. doi: 10.1177/1948550614531800

Leary, M. R., Kelly, K. M., Cottrell, C. A., and Schreindorfer, L. S. (2013). Construct validity of the need to belong scale: mapping the nomological network. J. Pers. Assess. 95, 610-624. doi: 10.1080/00223891.2013.819511

Leary, M. R., Kowalski, R. M., Smith, L., and Phillips, S. (2003). Teasing, rejection, and violence: case studies of the school shootings. Aggress. Behav. 29, 202-214. doi: 10.1002/ab.10061

Leitner, J. B., Hehman, E., Deegan, M. P., and Jones, J. M. (2014). Adaptive disengagement buffers self-esteem from negative social feedback. Pers. Soc. Psychol. Bull. 40, 1435-1450. doi: 10.1177/0146167214549319

Mallott, M., Maner, J., DeWall, N., and Schmidt, N. (2009). Compensatory deficits following rejection: the role of social anxiety in disrupting affiliative behavior. Depress. Anxiety 26, 438-446. doi: 10.1002/da.20555

Maner, J. K., DeWall, C. N., Baumeister, R. F., and Schaller, M. (2007). Does social exclusion motivate interpersonal reconnection? Resolving the "porcupine problem.” J. Pers. Soc. Psychol. 92, 42-55. doi: 10.1037/0022-3514.92.1.42

Masten, C. L., Telzer, E. H., and Eisenberger, N. I. (2011). An fMRI investigation of attributing negative social treatment to racial discrimination. J. Cogn. Neurosci. 23, 1042-1051. doi: 10.1162/jocn.2010.21520

McConnell, A. R., Brown, C. M., Shoda, M. T., Stayton, L. E., and Martin, C. E. (2011). Friends with benefits: on the positive consequences of pet ownership. J. Pers. Soc. Psychol. 101, 1239-1252. doi: $10.1037 / \mathrm{a} 0024506$

Molden, D. C., Lucas, G. M., Gardner, W. L., Dean, K., and Knowles, M. L. (2009). Motivations for prevention or promotion following social exclusion: being rejected versus being ignored. J. Pers. Soc. Psychol. 96, 415-431. doi: 10.1037/a0012958

Morf, C. C., and Rhodewalt, F. (2001). Unraveling the paradoxes of narcissism: a dynamic self-regulatory processing model. Psychol. Inq. 12, 177-196. doi: 10.1207/S15327965PLI1204_1

Nezlek, J. B., Wesselmann, E. D., Wheeler, L., and Williams, K. D. (2012). Ostracism in everyday life. Group Dyn. Theor. Res. Pract. 16, 91-104. doi: 10.1037/a0028029

Pfundmair, M., Aydin, N., Frey, D., and Echterhoff, G. (2014). The interplay of oxytocin and collectivistic orientation shields against negative effects of ostracism. J. Exp. Soc. Psychol. 55, 246-251. doi: 10.1016/j.jesp.2014.07.016

Pfundmair, M., Graupmann, V., Frey, D., and Aydin, N. (2015). The different behavioral intentions of collectivists and individualists in response to social exclusion. Pers. Soc. Psychol. Bull. doi: $10.1177 / 0146167214566186$

Pickett, C. L., Gardner, W. L., and Knowles, M. (2004). Getting a cue: the need to belong and enhanced sensitivity to social cues. Pers. Soc. Psychol. Bull. 30, 1095-1107. doi: 10.1177/0146167203262085

Ren, D., Wesselmann, E. D., and Williams, K. D. (2013). Interdependent self-construal moderates coping with (but not the initial pain of) ostracism. Asian J. Soc. Psychol. 16, 320-326. doi: 10.1111/ajsp.12037

Riva, P., Wesselmann, E. D., Wirth, J. H., CarterSowell, A. R., and Williams, K. D. (2014a). When pain does not heal: the common antecedents and consequences of chronic social and physical pain. Basic Appl. Soc. Psychol. 36, 329-346. doi: 10.1080/01973533.2014.917975

Riva, P., Williams, K. D., Torstrick, A. M., and Montali, L. (2014b). Orders to shoot (a camera): effect of ostracism on obedience. J. Soc. Psychol. 154, 208-216. doi: 10.1080/00224545.2014.883354

Schoel, C., Eck, J., and Greifeneder, R. (2014). A matter of vertical position: consequences of ostracism differ for those above versus below its perpetrators. Soc. Psychol. Pers. Sci. 5, 149-157. doi: $10.1177 / 1948550613488953$

Smart Richman, L., and Leary, M. R. (2009). Reactions to discrimination, stigmatization, ostracism, and other forms of interpersonal rejection: a multimotive model. Psychol. Rev. 116, 365-383. doi: 10.1037/a0015250

Sommer, K. L., and Bernieri, F. (2014). Minimizing the pain and probability of rejection evidence for relational distancing and proximity seeking within face-to-face interactions. Soc. Psychol. Pers. Sci. doi: $10.1177 / 1948550614549384$

Twenge, J. M., Baumeister, R. F., Tice, D. M., and Stucke, T. S. (2001). If you can't join them, beat them: effects of social exclusion on aggressive behavior. J. Pers. Soc. Psychol. 81, 1058-1069. doi: 10.1037/0022-3514.81.6.1058

Twenge, J. M., and Campbell, W. K. (2003). "Isn't it fun to get the respect that we're going to deserve?" Narcissism, social rejection, and aggression. Pers. Soc. Psychol. Bull. 29, 261-272. doi: $10.1177 / 0146167202239051$ 
Twenge, J. M., Zhang, L., Catanese, K. R., DolanPascoe, B., Lyche, L. R., and Baumeister, R. F. (2007). Replenishing connectedness: reminders of social activity reduce aggression after social exclusion. Br. J. Soc. Psychol. 46, 205-224. doi: 10.1348/014466605X90793

Warburton, W. A., Williams, K. D., and Cairns, D. R. (2006). When ostracism leads to aggression: the moderating effects of control deprivation. J. Exp. Soc. Psychol. 42, 213-220. doi: 10.1016/j.jesp.2005.03.005

Wesselmann, E. D., Butler, F. A., Williams, K. D., and Pickett, C. L. (2010). Adding injury to insult: unexpected rejection leads to more aggressive responses. Aggress. Behav. 36, 232-237. doi: 10.1002/ab.20347

Wesselmann, E. D., Hales, A., Ren, D., and Williams, K. D. (in press). "Ostracism threatens personal security: a temporal need threat framework," in Handbook of Personal Security, eds P. Carroll, R. Arkin, and A. Wichman (New York, NY: Psychology Press).

Wesselmann, E. D., and Williams, K. D. (2010). The potential balm of religion and spirituality for recovering from ostracism. J. Manag. Spirit. Relig. 7, 29-45. doi: 10.1080/147660809034 97623

Wesselmann, E. D., Williams, K. D., Ren, D., and Hales, A. (2014). "Ostracism and solitude," in A Handbook of Solitude: Psychological Perspectives on Social Isolation, Social Withdrawal, and Being Alone, eds R. J. Coplan and J. Bowker (Malden, MA: Wiley-Blackwell), 224-241.

Williams, K. D. (2007). Ostracism. Ann. Rev. Psychol. 58, 425-452. doi: 10.1146/annurev.psych.58. 110405.085641

Williams, K. D. (2009). "Ostracism: effects of being excluded and ignored," in Advances in Experimental Social Psychology, ed M. Zanna (New York, NY: Academic Press), 275-314.

Williams, K. D., Cheung, C. K. T., and Choi, W. (2000). Cyberostracism: effects of being ignored over the internet. J. Pers. Soc. Psychol. 79, 748-762. doi: 10.1037/0022-3514.79.5.748

Williams, K. D., and Sommer, K. L. (1997). Social ostracism by coworkers: does rejection lead to social loafing or compensation. Pers. Soc. Psychol. Bull. 23, 693-706. doi: 10.1177/0146167297237003

Williams, K. D., and Nida, S. A. (2011). Ostracism: Consequences and coping. Curr. Direct. Psychol. Sci. 20, 71-75. doi: 10.1177/09637214114 02480

Williams, K. D., and Wesselmann, E. D. (2011). “The link between ostracism and aggression," in The Psychology of Social Conflict and Aggression, eds J. P. Forgas, A. W. Kruglanski, and K. D. Williams (New York, NY: Psychology Press), 37-51.

Wirth, J. H., and Williams, K. D. (2009). "They don't like our kind": consequences of being ostracized while possessing a group membership.
Group Process. Interpers. Relat. 12, 111-127. doi: 10.1177/1368430208098780

Zadro, L., Boland, C., and Richardson, R. (2006). How long does it last? The persistence of the effects of ostracism in the socially anxious. J. Exp. Soc. Psychol. 42, 692-697. doi: 10.1016/j.jesp.2005.10.007

Conflict of Interest Statement: The authors declare that the research was conducted in the absence of any commercial or financial relationships that could be construed as a potential conflict of interest.

Received: 29 October 2014; accepted: 08 January 2015; published online: 03 February 2015.

Citation: Wesselmann ED, Ren D and Williams KD (2015) Motivations for responses to ostracism. Front. Psychol. 6:40. doi: 10.3389/fpsyg.2015.00040

This article was submitted to Cognitive Science, a section of the journal Frontiers in Psychology.

Copyright (c) 2015 Wesselmann, Ren and Williams. This is an open-access article distributed under the terms of the Creative Commons Attribution License (CC BY). The use, distribution or reproduction in other forums is permitted, provided the original author(s) or licensor are credited and that the original publication in this journal is cited, in accordance with accepted academic practice. No use, distribution or reproduction is permitted which does not comply with these terms. 